\title{
Performance Characteristics of Radiographic equipment in Selected Healthcare Institutions in Southwest Nigeria
}

\author{
Achuka Justina Ada ${ }^{1 *}$, Usikalu Mojisola Rachael ${ }^{1}$, Aweda Moses Adebayo ${ }^{2}$, Adeyinka Abiodun Oludotun ${ }^{3}$, \\ Famurewa Olusola Comfort ${ }^{4}$, Akinpelu Akinwumi ${ }^{1}$ \\ ${ }^{1}$ Department of Physics, Covenant University Ota, Ogun, Nigeria; ${ }^{2}$ Department of Radiation Biology, Radiotherapy and \\ Radiodiagnosis, College of Medicine, Lagos University Teaching Hospital, Idi-Araba, Lagos, Nigeria; ${ }^{3}$ Department of Radiology, \\ University College Hospital Ibadan, Nigeria; ${ }^{4}$ Department of Radiology, Obafemi Awolowo University Hospital Ile-Ife, Nigeria
}

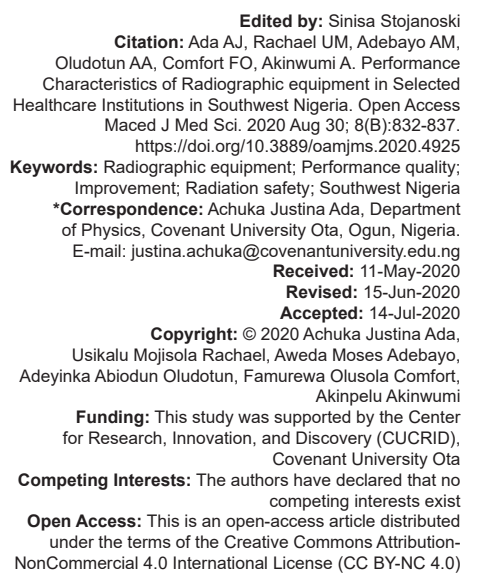

\begin{abstract}
BACKGROUND: Evaluation of radiographic equipment performance is the recommended strategy for the verification of factors used in radiodiagnosis. Sometimes, the performance of the equipment is compromised due to the lack of adoption of the appropriate procedures and/or techniques.

AIM: The aim of this study was to determine the performance quality of the radiographic equipment in the study area in order to optimize the radiation dose delivered to the patients using these facilities and enhance their safety.

METHODS: The performance characteristic of selected radiographic equipment was determined using MagicMax quality control kits and test object. Radiographic equipment in eight selected radiodiagnostic centers designated as C1-C8 was assessed.

RESULTS: The results showed that all the radiography units in the studied centers passed the kVp reproducibility and $\mathrm{mAs}$ linearity tests with the exception of center $\mathrm{C} 2$. The $\mathrm{kVp}$ deviation for the centers varied between 2.0 and $7.7 \%$, with the highest deviation in center $\mathrm{C} 5$ and lowest value in center C6. Center $\mathrm{C} 7$ has the highest deviation $(-13 \%)$ of $\mathrm{mAs}$, while the lowest value was obtained in center C6 $(0 \%)$. The dose was lowest in center $\mathrm{C} 1$ and highest in center $\mathrm{C} 3$. The half-value layer, $\mathrm{mAs}$, and filtration values had a stronger correlation with the incident air kerma dose compared to the other parameters. In addition, $50 \%$ of the equipment passed all the performance tests.

CONCLUSION: The study revealed that the performance characteristics of radiographic equipment in the studied area require improvement. Periodic monitoring of the equipment performance is recommended for adoption and enforcement to enhance quality practices and radiation safety.
\end{abstract}

\section{Introduction}

Radiographic equipment is widely in use globally. It has the highest frequency of imaging examinations as compared to other imaging modalities [1], [2], [3], [4], [5], [6]. Approximately $64 \%$ of all medical diagnostic examinations are from radiographic equipment [3]. Performance assessment of this equipment is therefore important to achieve its desired goal. Internationally, the radiation regulatory authorities recommended that imaging equipment be subjected to comprehensive quality assurance and quality control tests [7], [8], of which equipment performance assessment is a significant part. However, equipment performance assessment is still a challenge in many developing countries, where the equipment is known as old, poorly serviced, lacking good maintenance, and periodic quality control program [9].

Imaging equipment must be assessed regularly to enhance continued and reliable performance. This will ensure the proper functioning of the X-ray facility in accordance with international standards. According to the International Atomic Energy Agency (IAEA), the outcome of any imaging procedure depends on the performance of the equipment and its usage by the operators [7]. The study conducted by Wambani et al. specified the performance of the x-ray equipment as a key factor that influences patient dose [10]. Optimization of radiological protection is impossible without the evaluation of imaging equipment. It is a recommendation for newly installed x-ray diagnostic equipment to be subjected to standard safety operations before commissioning. This will enhance diagnostic quality and reduce patient dose [11].

Compliance surveys of x-ray equipment in Manitoba resulted in a patient dose downward trend [12]. The researchers reported that the downward trend is sustainable with quality control measures maintained. The study of Korir et al. noted an x-ray machine with failed generator exposure reproducibility and beam alignment test [9]. The consequences were high patient dose, image distortion, clipping of important anatomy, and grid cut-off among others [9]. A similar study reported patient dose reduction in the range of $31-77 \%$ for equipment having quality control assessment, while 
none calibrated equipment increased patient dose up to a factor of 1-5 times more than IAEA guidance level [13]. The study by Ngaile et al. confirmed that the lowering of $\mathrm{mAs}$ is suitable for x-ray equipment with higher timer reproducibility, while an increase in tube potential works well in equipment with high accuracy and voltage consistency [14].

Performance assessment of radiographic equipment cannot be over-emphasized. A little shift in any radiographic parameter has a significant impact on the patient absorbed dose [15], especially due to the incidence of cancer induction from radiographic examinations [6], [16]. It is therefore important that radiographic units be assessed before usage and periodically to ensure proper functioning. Hence, this study desired to determine the output quality of the radiographic equipment in the selected centers to optimize the radiation dose delivered to the patients.

\section{Materials and Methods}

This study was conducted using radiographic units from eight healthcare institutions spread across the states in Southwest Nigeria. The study centers were designated $\mathrm{C} 1-\mathrm{C} 8$ for confidentiality. Institutional Ethical Clearance certificates were obtained before the commencement of the study. The specifications of the radiographic units are as presented in Table 1. Equipment performance assessment was conducted using MagicMax quality control kits (IBA Dosimetry, Germany) and test object (Orion France, Paris). The MagicMax quality control kits consist of the universal basic unit, XR multi-detector (for radiography quality), XM multi-detector (for mammography quality), current probe, and other accessories. The multi-detector measures the dose, dose rate, time, practical peak voltage, peak kilovoltage $(\mathrm{kVp})$, average kilovoltage $(\mathrm{kV})$, half-value layer (HVL), and total filtration. The current probe measures the current and currenttime product, while the contrast and resolution were determined using the test objects.

\section{Determination of X-ray tube output}

The X-ray outputs (mGy/mAs) were determined at a focus detector distance (FDD) of $100 \mathrm{~cm}$ with a tube potential setting of $80 \mathrm{kVp}$ and tube loading of 10/15 mAs [17], [18]

\section{Reproducibility test for $k V p$}

The $k V p$ reproducibility test was conducted according to Taha [19] using the relation given by equation (1):

$$
R=\frac{S D}{Z_{a v}} \times 100 \%
$$

where $R$ is the reproducibility, $S D$ is the standard deviation of series of measurements, and $Z_{a v}$ is the mean value of the parameter measured. For this study, five exposures were made at a $k V p$ of 80 and keeping FDD and tube loading constant at $100 \mathrm{~cm}$ and $10 \mathrm{mAs}$, respectively.

\section{Accuracy test for $k V p$}

The accuracy test for $k V p$ was conducted according to standard using the relation given in equation (2) [19], [20]. Three exposures were made for this test at a kVp of 80 keeping FDD and tube loading constant at $100 \mathrm{~cm}$ and $10 \mathrm{mAs}$, respectively.

$$
A=\left|\frac{V_{m}-V_{s}}{V_{s}}\right| \times 100 \%
$$

$A$ represents the accuracy error, $V_{m}$ is the measured mean $\mathrm{kVp}$ and $V_{s}$ is the selected $\mathrm{kVp}$.

\section{Linearity test for $m A s$}

The linearity test was determined using the relation given in equation (3)

$$
L=\frac{\left|X_{1}-X_{2}\right|}{X_{1}+X_{2}}
$$

$X_{1}$ and $X_{2}$ represents two successive readings [19].

\section{Measurement of contrast sensitivity}

The radiographic units contrast sensitivity was determined by scanning the test object (FL18) to obtain the best image that will enable counting the circular details that are visible. On average, three exposures were made using the appropriate exposure

Table 1: Specifications of the selected imaging facilities

\begin{tabular}{lllllll}
\hline Center & Type & Name & Manufacturer & Model & Filtration (mm) & Focal spot (mm) \\
\hline C1 & Digital & Varian & GE & RAD-21 & 0.7 & NA \\
C2 & Computed & Philips & Philips & Optimus 50 & 2.5 & NA manufacture \\
C3 & Computed & Allengers & Toshiba & E7237X & 0.9 & 2016 \\
C4 & Conventional & Varian & GE & E7240FX & 1.2 & $2.0 / 1.0$ \\
C5 & Conventional & GE & GE & 2185226 & 0.23 & $1.2 / 0.6$ \\
C6 & Conventional & Varian & GE & RAD-12 & 1.6 & 0.8 \\
C7 & Conventional & Toshiba & Toshiba & E7239X & 0.9 & $1.2 / 0.6$ \\
C8 & Computed & BMI & Toshiba & E7252X & 0.9 & 2008 \\
\hline
\end{tabular}


parameters according to the operation of each X-ray unit. The images with the best contrast were selected and compared with the calibration chart.

\section{Measurement of limiting resolution}

The limiting resolution test was conducted by exposing the test object using the lowest $k V p$ and the appropriate mAs that gave the brightest image possible. Three exposures were made, and the best was chosen. Thereafter, the total number of spatial frequency groups that can be resolved was determined and compared with the standard chart.

\section{Results}

The measured radiographic output parameters are presented in Table 2. The deviations of the measured $\mathrm{kVp}$ and $\mathrm{mAs}$ from the nominal values are shown in Table 3. Figure 1 represents the plot of radiographic tube output with $\mathrm{kV}^{2}$ and Table 4 displayed the Pearson correlations for the radiographic output parameters. The performance assessment tests conducted are $\mathrm{kVp}$ reproducibility, kVp accuracy, mAs linearity, contrast sensitivity, and limiting resolution. The results are shown in Table 5. All the radiography units in the study centers passed the $\mathrm{kVp}$ reproducibility and $\mathrm{mAs}$ linearity tests except in center C2. However, $62.5 \%$ passed the $\mathrm{kVp}$ accuracy test, $25 \%$ were within the acceptable limit, and $12.5 \%$ failed the test. For contrast sensitivity, $87.5 \%$ passed, and $12.5 \%$ failed the test, while for resolution test, $75 \%$ passed, $12.5 \%$ were within acceptable limits, and $12.5 \%$ failed the test. The equipment performance assessment from this study was compared with other studies, as shown in Table 6.

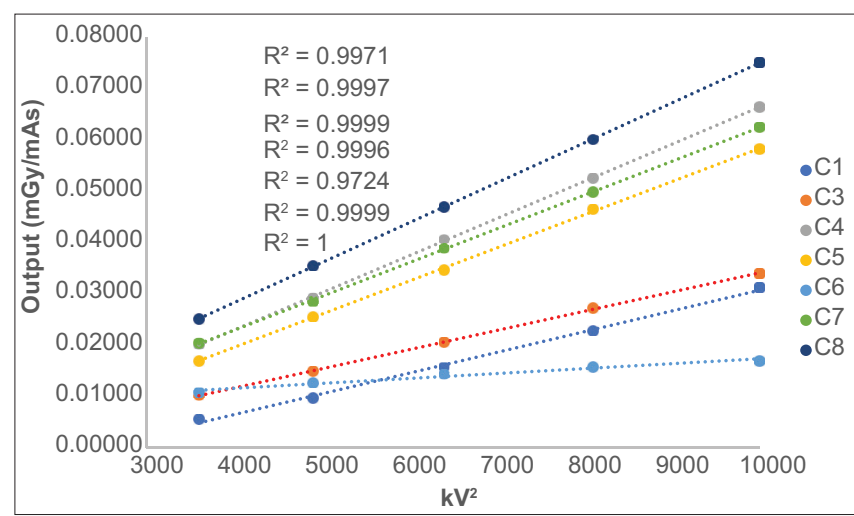

Figure 1: Tube output ( $m G y / m A s)$ variation with $\mathrm{kV}^{2}$

\section{Discussion}

The $k \mathrm{p}$ has the highest deviation in center C5 and lowest value in center C6, while mAs has the highest deviation in center $\mathrm{C} 7$ and lowest value in center $\mathrm{C6}$. The deviation of $\mathrm{kVp}$ and $\mathrm{mAs}$ from the nominal values (Table 3 ) might be due to the conduction

Table 2: Radiography units output parameters at $80 \mathrm{kVp}, 10 / 16 \mathrm{mAs}$, and $100 \mathrm{~cm}$ FDD

\begin{tabular}{|c|c|c|c|c|c|c|c|c|c|c|}
\hline Centers & Dose (mGy) & PPV (kV) & $\mathrm{mA}$ & Dose rate $(\mathrm{mGy} / \mathrm{s})$ & Duration (s) & $\mathrm{mAs}$ & $\mathrm{kV}_{\mathrm{av}}$ & $\mathrm{HVL}(\mathrm{mm})$ & Filtr $(\mathrm{mm})$ & $k V p$ \\
\hline C1 & 0.153 & 82.59 & 193.4 & 3.040 & 0.0503 & 9.7 & 82.85 & 6.0 & 10.6 & 83.24 \\
\hline $\mathrm{C} 2$ & 0.282 & 83.68 & NA & 10.54 & 0.0267 & NA & 83.91 & 5.0 & 6.9 & 84.46 \\
\hline C3 & 0.839 & 77.04 & 85.9 & 1.769 & 0.4742 & 40.8 & 76.70 & 3.1 & 3.1 & 81.92 \\
\hline C4 & 0.396 & 83.63 & 97.1 & 3.965 & 0.0997 & 9.7 & 83.88 & 3.8 & 3.9 & 84.23 \\
\hline C5 & 0.530 & 72.68 & 113.5 & 3.936 & 0.1347 & 15.3 & 72.86 & 3.2 & 3.7 & 73.81 \\
\hline C6 & 0.730 & 81.02 & 259.3 & 19.02 & 0.0384 & 10.0 & 81.23 & 3.1 & 2.8 & 81.59 \\
\hline $\mathrm{C} 7$ & 0.342 & 82.15 & 86.3 & 3.406 & 0.1004 & 8.7 & 82.37 & 3.5 & 3.6 & 82.82 \\
\hline C8 & 0.431 & 82.26 & 166.4 & 7.828 & 0.0551 & 9.2 & 82.55 & 3.2 & 2.9 & 83.19 \\
\hline
\end{tabular}

Table 3: Comparison of selected and measured $\mathrm{kVp}$ and $\mathrm{mAs}$ for radiography units at $80 \mathrm{kVp}, 10 / 16 \mathrm{mAs}$

\begin{tabular}{|c|c|c|c|c|c|c|}
\hline Centers & Selected & kVp Measured & Deviation (\%) & Selected & mAs Measured & Deviation (\%) \\
\hline C1 & 80.0 & 83.24 & 4.1 & 10.0 & 9.7 & -3.0 \\
\hline $\mathrm{C} 2$ & 80.0 & 84.46 & 5.6 & NA & NA & NA \\
\hline C3 & 80.0 & 81.92 & 2.4 & 16.0 & $40.8^{*}$ & $155^{\star}$ \\
\hline C4 & 80.0 & 84.23 & 5.3 & 10.0 & 9.7 & -3.0 \\
\hline C5 & 80.0 & 73.81 & -7.7 & 16.0 & 15.3 & -7.0 \\
\hline C6 & 80.0 & 81.59 & 2.0 & 10.0 & 10.0 & 0.0 \\
\hline C7 & 80.0 & 82.82 & 3.5 & 10.0 & 8.7 & -13 \\
\hline C8 & 80.0 & 83.19 & 4.0 & 10.0 & 9.2 & -8.0 \\
\hline
\end{tabular}

Table 4: Pearson correlation of output parameters

\begin{tabular}{|c|c|c|c|c|c|c|c|c|c|c|}
\hline Parameters & Dose (mGy) & PPV (kV) & $\mathrm{mA}$ & Dose rate (mGy/s) & Duration (s) & $\mathrm{mAs}$ & $\mathrm{kV}_{\mathrm{av}}$ & $\mathrm{HVL}(\mathrm{mm})$ & Filtration $(\mathrm{mm})$ & $k \vee p$ \\
\hline Dose (mGy) & 1.000 & -0.549 & 0.213 & 0.243 & 0.667 & 0.730 & -0.572 & -0.778 & -0.725 & -0.330 \\
\hline PPV (kV) & & 1.000 & -0.018 & 0.243 & -0.516 & -0.582 & 0.999 & 0.470 & 0.331 & 0.925 \\
\hline $\mathrm{mA}$ & & & 1.000 & 0.439 & -0.239 & -0.002 & -0.006 & -0.122 & -0.041 & -0.119 \\
\hline Dose rate $(\mathrm{mG} / \mathrm{s})$ & & & & 1.000 & -0.482 & -0.412 & 0.254 & -0.154 & -0.202 & 0.112 \\
\hline Duration (s) & & & & & 1.000 & 0.969 & -0.554 & -0.383 & -0.317 & -0.162 \\
\hline $\mathrm{mAs}$ & & & & & & 1.000 & -0.616 & -0.421 & -0.327 & -0.248 \\
\hline $\mathrm{kV}_{\mathrm{ar}}$ & & & & & & & 1.000 & 0.475 & 0.336 & 0.907 \\
\hline $\mathrm{HVL}(\mathrm{mm})$ & & & & & & & & 1.000 & 0.983 & 0.391 \\
\hline Filtration (mm) & & & & & & & & & 1.000 & 0.261 \\
\hline$k V p$ & & & & & & & & & & 1.000 \\
\hline
\end{tabular}


of incomprehensive equipment performance evaluation during the installation of the equipment. In addition, the lack of equipment performance evaluation after equipment maintenance might be responsible for some of the deviations observed. Newly installed imaging equipment is subjected to status and performance tests to establish the functional status of the equipment and generate the operational database [28]. The wide variation between the set factors and the actual output from $\mathrm{x}$-ray machines has been reported by Nzotta and Chiaghanam [29]. The authors attributed the shortcomings to irregular quality control practices, poor equipment maintenance, and non-compliance to radiation protection rules and regulations. A small error in the selected $k V p$ and $m A s$ has a significant effect on the image quality. In addition, X-ray parameters are interdependent; a fault in any parameter has much influence on the final image quality [30]. Therefore, it is essential that the measured output parameters be in reasonable agreement with the nominal values to achieve the desired imaging goal.

Table 5: Performance assessment results at the study centers

\begin{tabular}{|c|c|c|c|c|c|c|c|c|}
\hline Centers & C1 & $\mathrm{C} 2$ & $\mathrm{C} 3$ & $\mathrm{C} 4$ & $\mathrm{C} 5$ & $\mathrm{C} 6$ & $\mathrm{C} 7$ & $\mathrm{C} 8$ \\
\hline \multicolumn{9}{|c|}{ kVp reproducibility (5\%) } \\
\hline Assessment (\%) & 0.12 & 0.19 & 0.09 & 0.12 & 0.26 & 0.05 & 0.07 & 0.14 \\
\hline Comment & Pass & Pass & Pass & Pass & Pass & Pass & Pass & Pass \\
\hline \multicolumn{9}{|l|}{$\mathrm{kVp}$ accuracy $(5 \%)$} \\
\hline Assessment (\%) & 4.13 & 5.36 & 2.25 & 5.20 & 7.86 & 2.02 & 3.52 & 4.08 \\
\hline $\begin{array}{l}\text { Comment } \\
\text { mAs linearity }(<0.1)\end{array}$ & Pass & $\mathrm{AC}$ & Pass & AC & Fail & Pass & Pass & Pass \\
\hline Assessment & 0.001 & NA & 0.051 & 0.011 & 0.006 & 0.002 & 0.003 & 0.007 \\
\hline Comment & Pass & NA & Pass & Pass & Pass & Pass & Pass & Pass \\
\hline \multicolumn{9}{|c|}{ Contrast sensitivity (3\%) } \\
\hline Assessment & 0.018 & 0.011 & 0.007 & 0.045 & 0.013 & 0.011 & 0.018 & 0.009 \\
\hline Comment & Pass & Pass & Pass & Fail & Pass & Pass & Pass & Pass \\
\hline \multicolumn{9}{|l|}{ Resolution (>1.80) } \\
\hline Assessment & 2.00 & 1.80 & 0.06 & 2.50 & 2.24 & 4.00 & 2.24 & 2.50 \\
\hline Comment & Pass & $\mathrm{AC}$ & Fail & Pass & Pass & Pass & Pass & Pass \\
\hline
\end{tabular}

The radiography equipment in center $\mathrm{C} 3$ gave an output quite different from all the other x-ray machines. Parameters, such as pulse count, pulse frequency, and dose per pulse, among others, were captured by the MagicMax QC kit on the equipment. This might be responsible for the higher $\mathrm{mAs}$ values recorded. The output of C3 machine also confirms the variability of x-ray equipment due to different configurations [31]. The effect of variant X-ray equipment configurations was responsible for the choice of different $m$ As values in some centers. For center $\mathrm{C} 2$, the cathode and anode cables were sealed such that the current probe could not be attached. This was the reason why the mAs values were not measured at the center. The dose (Table 2) was lowest in center $\mathrm{C} 1$ and highest in center C3. The radiographic equipment in center C1 is fully digital. Digital equipment records a lower radiation dose compared to conventional equipment [15]. In addition, $\mathrm{C} 1$ equipment has the highest filtration value compared to equipment in other centers. Increasing filtration results in a reduction of dose up to a factor of 3 [32]. For C3, the high dose might be attributed to the higher mAs value. Tube current influences dose [15]. Although center C6 had the lowest deviations of exposure factors from the nominal value, yet the dose has the second-highest value. The high dose value observed is attributable to the low filtration value. The equipment has the lowest measured filtration value. However, all the equipment in the study centers have their filtration values within the recommend limits [18], [33]. In addition, the measured HVL values for all the equipment in the study centers are within the recommended specifications [33]. The impact of HVL, filtration, and $m A s$ on incident air kerma dose was observed, as shown in Table 4. The Pearson correlation (Table 4) for the radiographic output parameters showed that the HVL, mAs, and filtration values had a stronger correlation with the dose compared to the other parameters.

The X-ray equipment in center C6 was above 10 years, yet it yielded better results compared to those within its age brackets and even newer equipment elsewhere. However, all the equipment in the study centers passed the $k V p$ reproducibility test (Table 5). Similar observation has been reported by other studies [19], [20], [25], [27]. The effect of good $\mathrm{kVp}$ reproducibility was evident, as shown in Figure 1, in which the $\mathrm{kV}^{2}$ has a very strong correlation with the tube output. In addition, equipment in centers C1, C6, C7, and C8 passed all the performance tests (Table 5). This shows that the equipment has better maintenance compared to others. Center C5 failed the kVp accuracy test; hence, there is a higher probability for a repeat of examination due to over-exposure and consequently high dose to the patient. The kVp accuracy failure is well documented in the literature [21], [22], [23], [24], [26]. Center C4 failed the contrast sensitivity test; this might result in poor image quality. More so, as the $\mathrm{kVp}$ accuracy value (5.20) of the equipment is a bit above the reference value $(>5 \%)$. The equipment in the center $\mathrm{C} 3$ failed the resolution test. Resolution defects may result in the rejection of radiograph and poor diagnosis, thereby defeating the aim of the examination. The condition of equipment in center $\mathrm{C} 2$ is worrisome given that the $\mathrm{mAs}$ value could not be determined. In addition, the $\mathrm{kVp}$ accuracy and resolution values are above the reference values. Although within acceptable limits, this outcome indicates that the equipment is poorly maintained and lacks adequate quality control measures.

It is through performance assessment that radiographic equipment can be ascertained to function

Table 6: Comparison of equipment performance failure (\%) with other studies

\begin{tabular}{|c|c|c|c|c|c|c|c|c|c|c|}
\hline Authors & This study & [19] & [20] & [21] & [22] & [23] & [24] & [25] & {$[26]$} & [27] \\
\hline kVp Reproducibility & 0.0 & 0.0 & 0.0 & NR & NR & 42.9 & 5.6 & 0.0 & NR & 0.0 \\
\hline$k \vee p$ accuracy & 12.5 & 16.7 & 21.7 & 38.6 & 25.0 & 42.9 & 11.1 & 6.7 & 27.0 & 29.5 \\
\hline mAs linearity & 12.5 & NR & NR & NR & NR & NR & NR & NR & NR & NR \\
\hline Contrast Sensitivity & 12.5 & NR & NR & NR & NR & NR & NR & NR & NR & NR \\
\hline Resolution & 12.5 & NR & NR & NR & NR & NR & NR & NR & NR & NR \\
\hline
\end{tabular}


optimally. Periodic and regular monitoring of the equipment performance is a continual obligation. This would enhance quality performance and promotes radiation safety for both patients and radiological staff.

\section{Conclusion}

The study revealed that the performance characteristics of radiographic equipment in the study area require improvement. Periodic and regular monitoring of the equipment performance parameters is recommended for adoption and enforcement, thereby preventing exposure error, film reject, misdiagnosis, and radiation risks. The study, therefore, concluded that monitoring of performance characteristics of the equipment will enhance quality practice and radiation safety for patients and staff.

\section{Acknowledgment}

We sincerely appreciate the Center for Research, Innovation, and Discovery (CUCRID), Covenant University Ota, for financial support. Many thanks to the Radiation staff and Management of the various healthcare institutions used for the study.

\section{References}

1. Hart D, Wall BF, Hillier MC, Shrimpton PC. Frequency and Collective Dose for Medical and Dental X-ray Examinations in the UK, 2008. England: Health Protection Agency: HPACRCE-012; 2010. p. 1-32.

2. Health Services Executive. Population Dose from General X-ray and Nuclear Medicine: 2010. United Kingdom: HSE, Medical Exposure Radiation Unit; 2010. p. 1-15.

3. World Health Organization. Communicating Radiation Risks in Paediatric Imaging: Information to Support Healthcare Discussions About Benefit and Risk. Geneva: World Health Organization; 2016. p. 16-7.

4. National Health Service. Diagnostic Imaging Datasets Statistical Release: Provisional Monthly Statistics 2015 to June 2016 England: National Health Service; 2016. p. 4-10.

5. National Health Service. Diagnostic Imaging Datasets Statistical Release: Provisional Monthly Statistics January 2016 to January 2017. England: National Health Service; 2017. p. 4-10.

6. Achuka JA, Aweda MA, Usikalu MR. Cancer risks from head radiography procedures. IOP Conf Series Earth Environ Sci. 2018;173:012038. https://doi. org/10.1088/1755-1315/173/1/012038.

7. International Atomic Energy Agency. Applying Radiation Safety Standards in Diagnostic Radiology and Interventional Procedures Using X-rays. Safety Standards Series No. 39.
Vienna: International Atomic Energy Agency; 2006. p. 1-110.

8. International Atomic Energy Agency. Quality Assurance Programme for Computed Tomography: Diagnostic and Therapy Applications. IAEA Human Health Series No 19. Vienna: International Atomic Energy Agency; 2012. p. 1-171.

9. Korir GK, Wambani JS, Ochieng BO. Optimization of patient protection and image quality in diagnostic radiology. East Afr Med J. 2010;87(3):127-33. https://doi.org/10.4314/eamj. v87i3.62198

PMid:23057309

10. Wambani JS, Onditi EG, Korir GK, Korir IK. Patient doses in general radiography examinations. South Afr Radiogr. 2015;53(1):22-6.

11. Panicker TM, Tina-Angelina JT, Korath MK, Mohandas $K$, Jagadeesan K. Entrance skin dose estimation in $\mathrm{x}$-ray lumbar spine lateral procedure: Conventional vs digital $x$-ray units: $A$ pilot study. JIMSA. 2013;26(4):219-20.

12. Johnson HM, Neduzak C, Gallet J, Sandeman J. Trends and the determination of effective doses for standard $\mathrm{x}$-ray procedures. In: Proceedings of the International Conference on Radiological Protection of Patients in Diagnostic and Intervention of Radiology, Nuclear Medicine and Radiotherapy. Vienna, Austria: International Atomic Energy Agency, IAEA-CN-85-29; 2001.

13. Yacoob HY, Mohammed HA. Assessment of patients x-ray doses at three government hospitals in Duhok city lacking requirements of effective quality control. J Radiat Res Appl Sci. 2017;10(3):183-7. https://doi.org/10.1016/j.jrras.2017.04.005

14. Ngaile JE, Muhogora WE, Nyanda AM. Some experiences from radiation protection of patients undergoing $\mathrm{x}$-ray examinations in Tanzania. In: Proceedings of the International Conference on Radiological Protection of Patients in Diagnostic and Interventional Radiology, Nuclear Medicine and Radiotherapy, Malagu, Spain. Vienna, Austria: International Atomic Energy Agency, IAEA-CN-85-113; 2001. p. 58-63. https://doi. org/10.1093/oxfordjournals.rpd.a032639

15. Achuka JA, Aweda MA, Usikalu MR, Aborisade CA. Assessment of patient absorbed radiation dose during hysterosalpingography: A pilot study in Southwest Nigeria. J Biomed Phys Eng. 2020;10(2):131-40. https://doi.org/10.31661/ jbpe.v0i0.1054 PMid:32337179

16. Achuka JA, Aweda MA, Usikalu MR, Aborisade CA. Cancer risks from chest radiography of young adults: A pilot study at a health facility in South West Nigeria. Data Brief. 2018;19:12506. https://doi.org/10.1016/j.dib.2018.05.123 PMid:30229004

17. Jibiri NN, Olowookere CJ. Patient dose audit of the most frequent radiographic examinations and the proposed local diagnostic reference levels in Southwestern Nigeria: Imperative for dose optimization. J Radiat Res Appl Sci. 2016;9:274-81. https://doi.org/10.1016/j.jrras.2016.01.003

18. Rasuli B, Pashazadeh AM, Ghorbani M, Juybari RT, Naserpour M. Patient dose measurement in common medical x-ray examinations in Iran. J Appl Clin Med Phys. 2016;17(1):374-86. https://doi.org/10.1120/jacmp.v17i1.5860 PMid:26894357

19. Taha TM. Study of the Quality Assurance of Conventional X-ray Machines Using Non-invasive KV Meter. Cairo, Egypt: Tenth Radiation Physics and Protection Conference; 2010. p. 105-10.

20. Njiki CD, Manyol JE, Yigbedeck YE, Ateba JF, Abouou DW, Ndah TN. Quality control of conventional radiology devices in selected hospitals of the republic of Cameroon. Int J Innov Sci. 2018;5(3):1-4.

21. Asadinezhad M, Bahreyni-Toossi MT, Ebrahiminia A, Giahi M. Quality control assessment of conventional radiology devices in Iran. Iran J Med Phys. 2017;14(1):1-7. 
22. Akpochafor $\mathrm{MO}$, Omojola $\mathrm{AD}$, Soyebi $\mathrm{KO}$, Adeneye SO, Aweda MA, Ajayi HB. Assessment of peak kilovoltage accuracy in ten selected X-ray centres in Lagos metropolis, SouthWestern Nigeria: A quality control test to determine energy output accuracy of an X-ray generator. J Health Res Rev. 2016;3(2):60-5. https://doi.org/10.4103/2394-2010.184231

23. Gholami M, Nemati F, Karami V. The evaluation of conventional $\mathrm{x}$-ray exposure parameters including tube voltage and exposure time in private and governmental hospitals of Lorestan Province, Iran. Iran J Med Phys. 2015;12(1):85-92.

24. Ismail HA, Ali OA, Omer MA, Garelnabi ME, Mustafa NS. Evaluation of diagnostic radiology department in term of quality control of x-ray units at Khartoum state Hospitals. Int J Sci Res. 2015;4(1):1875-8.

25. Rasuli B, Pashazadeh AM, Birgani MJ, Ghorbani M, Naserpour M, Fatahi-AsI J. Quality control of conventional radiology devices in selected hospitals of Khuzestan Province, Iran. Iran J Med Phys. 2015;12(2):101-8.

26. Gholamhosseinian-Najjar $\mathrm{H}$, Bahreyni-Toossi MT, Zare $\mathrm{MH}$, Sadeghi HR, Sadough HR. Quality control status of radiology centers of hospitals associated with Mashhad university of medical sciences. Iran J Med Phys. 2014;11(1):182-7.

27. Khoshnazar AK, Hejazi P, Mokhtarian M, Nooshi S. Quality control of radiography equipment in Golestan Province of Iran. Iran J Med Phys. 2013;10(1-2):37-44.

28. Kareem AA, Hulugalle SN, Al-Hamadani HK. A quality contro test for general x-ray machine. World Sci News. 2017;90:11-30.

29. Nzotta CC, Chiaghanam NO. Occupational radiation dose to $x$-ray workers in radiological units in Southeastern Nigeria. Afr $J$ Med Phys Biomed Eng Sci. 2010;2:64-6.

30. Begum M, Mollah AS, Zaman MA, Rahman AK. Quality control tests in some diagnostic X-ray units in Bangladesh. J Med Phys. 2011;4(1):59-66. https://doi.org/10.3329/bjmp.v4i1.14688

31. United States Environmental Protection Agency. Radiation Protection Guidance for Diagnostic and Interventional X-ray Procedures, Federal Guidance Report No 14, EPA402-R-10003. Washington, DC: United States Environmental Protection Agency; 2014.

32. Milatovic AA, Spasic-Jokic VM, Jovanovic SI. Patient dose measurement and dose reduction in chest radiography. Nuclear Technol Radiat Protect. 2014;29(3):220-5. https://doi. org/10.2298/ntrp1403220m

33. Atomic Energy Regulatory Board. Radiation Safety in Manufacture, Supply and Use of Medical Diagnostic X-ray Equipment. AERB Safety Code No: AERB/RF-MED/SC-3. Mumbais Atomic Energy Regulatory Board; 2016. p. 35-7. 